\title{
Assessment of Border Patrol Group Ammunition Amount Required for Border Fighting
}

\author{
V. Gorodnov ${ }^{1 *}$, V. Kyrylenko ${ }^{2}$ and Yu. Repilo ${ }^{3}$ \\ ${ }^{1}$ National Academy of the National Guard of Ukraine, Kharkiv, Ukraine \\ ${ }^{2}$ Bohdan Khmelnytskyi National Academy of the State Border Guard Service of Ukraine, \\ Khmelnytskyi, Ukraine \\ ${ }^{3}$ National Defence University of Ukraine named after Ivan Cherniakhovskyi, Kyiv, Ukraine
}

The manuscript was received on 12 September 2020 and was accepted after revision for publication as research paper on 15 March 2021.

\begin{abstract}
:
The purpose of the article was to assess the amount of ammunition required by the border guard during the battle with the sabotage and reconnaissance group until the arrival of reinforcements. To achieve the goal, a method of mathematical modeling of combat processes in the class of Markov processes with continuous time and discrete states was chosen. As a result, the method made it possible to construct the required models, check their adequacy, due to the found internal law of battle, and evaluate the performance on a specific practical example.
\end{abstract}

Keywords:

ammunition, battle model, border guards, state border

\section{Introduction}

The security of the state on its border is ensured by border agencies that counter the threats of international terrorism; uncontrolled proliferation of weapons, sabotage means, explosive, narcotic, psychotropic substances; illegal migration and other threats.

The state border is guarded by border patrol groups using technical means in its equipped areas, as well as by visual observation - in unequipped areas. An example of guarding one of the longest borders with equipped and unequipped sections are groups of US Immigration and Naturalization patrol agents who patrol 8000 miles of land border sections around the clock, tracking intruders, especially in remote unequipped areas [1]. In preparation for crossing the state border, organized terrorist groups choose a place, time, means of camouflage, a sequence of actions, as well as options for fire defeat in case of meeting with border guards.

\footnotetext{
* Corresponding author: National Academy of the National Guard of Ukraine, 3 Zakhysnykiv Ukrainy Square, UA-610 01, Kharkiv, Ukraine.Phone: +3806795492 16, E-mail:vgor46@ukr.net
} 


\begin{tabular}{|c|c|c|c|}
\hline \multicolumn{4}{|l|}{ Nomenclature } \\
\hline Coefficients of the differential equations system (39) & $a_{i j}$ & Border guard defeat probability & $P^{*}$ \\
\hline to th hotlofig & $D_{\mathrm{mv}}$ & $\begin{array}{l}\text { Probability of the terrorist timely } \\
\text { detection and the beginning of fire } \\
\text { contact }\end{array}$ & $P_{\mathrm{d}}$ \\
\hline ble limit $(e=2.71828 \ldots)$ & $\mathrm{e}$ & Probability of killing terrorist & $P_{\mathrm{e}}$ \\
\hline $\begin{array}{l}\text { Average number of fire contacts at the moment of } \\
\text { exhaustion of ammunition }\end{array}$ & $F_{\mathrm{c}}$ & $\begin{array}{l}\text { Probability of a border guard being hit } \\
\text { by an undetected terrorist }\end{array}$ & $P_{\mathrm{h}}$ \\
\hline $\begin{array}{l}\text { Size of the present ammunition load converted to the } \\
\text { number of fire contacts }\end{array}$ & $F_{\text {fc }}$ & $\begin{array}{l}\text { Probability of the battle model } \\
\text { state } S_{i j}\end{array}$ & $P_{i j}$ \\
\hline Intensity of fire contact flow & $I$ & $\begin{array}{l}\text { First derivative of the state probability } \\
P_{i j}\end{array}$ & $\dot{P}_{i j}$ \\
\hline Intensity of fire contact flow for one border guard & $I_{1}$ & $\begin{array}{l}\text { Weight of the regular ammunition } \\
\text { load to the border guard's weapons }\end{array}$ & $Q_{\text {alw }}$ \\
\hline $\begin{array}{l}\text { Intensity of timel } \\
\text { guard and the sta }\end{array}$ & $I_{\mathrm{d}}$ & Final weight of the am & $Q_{f w a l}$ \\
\hline $\begin{array}{l}\text { Intensity of the border guard defeat flow by an } \\
\text { undetected terrorist }\end{array}$ & $I_{\mathrm{h}}$ & $\begin{array}{l}\text { Physiologic } \\
\text { the border g } \\
\text { weight }\end{array}$ & $Q_{m}$ \\
\hline $\begin{array}{l}\text { mpletion of fire contacts of } \\
\text { st }\end{array}$ & $I_{\mathrm{r}}$ & Weight of the standard equipment & $Q_{\text {st.eq }}$ \\
\hline $\begin{array}{l}\text { ome by the terrorists within } \\
\text { er guards }\end{array}$ & $L_{\mathrm{str}}$ & ition load & $Q_{w}$ \\
\hline $\begin{array}{l}\text { Applying the mathematical expectation operation to } \\
\text { the defeated border guards number }\end{array}$ & $M\left[n_{\mathrm{bg}}\right]$ & $\begin{array}{l}\text { guards are } \\
\text { s are in the }\end{array}$ & $S_{i j}$ \\
\hline $\begin{array}{l}\text { ectation operation to } \\
\text { racket }\end{array}$ & $M\left[N_{\mathrm{e}}\right]$ & ent time & $t$ \\
\hline Initial number of $\mathrm{b}$ & $n_{0}$ & $\begin{array}{l}\text { Arr } \\
\text { pla }\end{array}$ & $t_{\text {ar.t }}$ \\
\hline xpectation of the number of defeated & $n_{\mathrm{bg}}$ & $f$ the fire & $T_{\text {avr }}$ \\
\hline $\begin{array}{l}\text { Mathematical expectation of the number of defeated } \\
\text { border guards during one fire contact }\end{array}$ & $n_{\text {bg. } 1}$ & $\begin{array}{l}\text { il the loss of } \\
\text { mbat capabil- }\end{array}$ & $t_{\mathrm{cr}}$ \\
\hline xpectation of the number of killed & $N_{\mathrm{e}}$ & ammuni- & $t_{F}$ \\
\hline $\begin{array}{l}\text { Mathematical expectation of the number of killed } \\
\text { terrorists until the moment of defeat all border guards } \\
\text { in the patrol group }\end{array}$ & $N_{\mathrm{e}_{\infty}}$ & $\begin{array}{l}f \text { the en-route movement to } \\
\text { ield }\end{array}$ & $t_{\mathrm{mv}}$ \\
\hline $\begin{array}{l}\text { Mathematical expectation of the number of killed } \\
\text { terrorists during one fire contact }\end{array}$ & $N_{\mathrm{e} .1}$ & lert forces to & $t_{\text {pr.t }}$ \\
\hline ical expectation of the fire contacts number & $n_{\mathrm{fc}}$ & Du & $T_{\text {random }}$ \\
\hline $\begin{array}{l}\text { Mathematical expectation of the fire contacts limit- } \\
\text { ing number until the moment of defeat all border } \\
\text { guards in the patrol group }\end{array}$ & $n_{\mathrm{fc \infty}}$ & $\begin{array}{l}\text { Average speed of movement to the } \\
\text { battle field }\end{array}$ & $W$ \\
\hline Number of terrorists in the group & $N_{\mathrm{tr}}$ & errorists movement & $v_{\mathrm{tr}}$ \\
\hline $\begin{array}{l}\text { Normalized value of the fire contacts number math- } \\
\text { ematical expectation }\end{array}$ & $n_{\mathrm{fc}}^{*}$ & $\begin{array}{l}\text { Threshold level of losses at which a } \\
\text { group of border guards loses combat } \\
\text { capability }\end{array}$ & $\beta$ \\
\hline $\begin{array}{l}\text { Normalized value of the mathematical expectation of } \\
\text { the number of killed terrorists }\end{array}$ & $N_{\mathrm{e}}^{*}$ & $\begin{array}{l}\text { Increase value of the existing ammu- } \\
\text { nition load }\end{array}$ & $\Delta F_{\text {inc }}$ \\
\hline $\begin{array}{l}\text { Normalized value of the mathematical expectation of } \\
\text { the number of defeated border guards }\end{array}$ & $n^{*}$ & $\begin{array}{l}\text { Parameter of the exponential distribu- } \\
\text { tion law } \\
\text { System load factor }\end{array}$ & $\mu$ \\
\hline
\end{tabular}


In conditions of protracted military conflicts, for example, between Israel and Palestine or in the East of Ukraine, sabotage and reconnaissance groups (SRG) can cross the state border.

Therefore, a group of border guards while on patrol may suddenly engage a group of terrorists or SRG, usually while reporting to the border command post to call for reinforcements. The amount of ammunition at the group's border guards must be sufficient to conduct a battle until the moment the reinforcements arrive.

On the one hand, surplus ammunition increases their weight, reduces maneuverability and increases the chances of combat losses for border guards. On the other hand, lack of ammunition reduces the available waiting time for reinforcements and increases the probability of border patrol losses. To illustrate this, let us mention the fact that during the military conflict, the border guards of Ukraine lost 70 people killed and more than 400 wounded [2].

However, it is very difficult to assess the rational amount of ammunition at the disposal of border guards, since none of the following values is easily predictable: starting time and duration of the battle, the distance from the battle site to the unit's deployment point, the composition of the SRG, the intensity of ammunition consumption, the losses of the parties during the battle are not known in advance and are random values.

As a result, an urgent problem arises of assessing the rational amount of ammunition required by border guards during the protection of the state border, taking into account the possibility of a battle with SRG.

\section{Preliminaries and Related Works}

The task of timely supplying border guards with ammunition is often viewed as one of the elements of their material support. In [3,4] and other well-known publications, the focus was on the specific elements of building border operations and combating SRG. Thus, in [3], a planning technique for border operations with the distribution of personnel among the elements of its operational formation was developed. In [4] the analysis of counteraction to sabotage and reconnaissance groups by border guards units in modern conditions is carried out.

The issue of material support in modern conditions was also considered in $[5,6]$ and in other existing publications, however, mainly for the Ground Forces. In particular, in [5], an indicator is proposed for assessing the timeliness of the delivery of materiel for the Ground Forces grouping. In [6], an approach is proposed for assessing the impact of levels of material support on the number of combat-ready personnel of an interspecific tactical group.

However, the issue of assessing the amount of ammunition required by the border guard to conduct a battle with a sabotage and reconnaissance group until the arrival of reinforcements has not been considered in these and other publications. A reasoned estimate of the required amount of ammunition can be obtained using a sufficiently adequate battle model. Such a model should reflect the most essential features of the defensive battle of the Patrol Group border guards with the SRG terrorists when they try to overcome the state border. The model should contain calculation formulas that make it possible to assess the expected results of the battle depending on the composition of the party forces, on the parameters of their professional training level and on the amount of ammunition available to the border guards. 
Therefore, the goal of the article is to develop a model of the battle between border guards and the SRG, to assess its adequacy and to apply it. The main objective is to assess the amount of ammunition required by the border guard during the battle with the sabotage and reconnaissance group until the arrival of reinforcements.

To achieve this goal, we have introduced a notation system for necessary variable quantities, which we will further use in our reasoning.

\section{Research Results}

\subsection{A Brief Description of the Border Guards Battle with Terrorists of the SRG}

When meeting with a sabotage and/or reconnaissance group, the patrol group consisting of $n_{0}$ border guards takes the original point in battle order, taking into account the protective properties of the terrain. As soon as possible, they report the operational situation to the duty officer in the command and control center of the unit, call for reinforcement, and they engage in a battle with the terrorists of the SRG. The objective of the patrol group is to prevent the violation of the state border by capturing, destroying, or forcing terrorists of the SRG to give up on the violation and retreat to their territory.

The battle with the SRG may terminate for one of the following reasons: the SRG terrorists leaving the border guards' effective zone of fire and retreat to their territory, the defeat or capture of terrorists, the defeat of border guards, the depletion of ammunition from one of the parties, the approach of reinforcement to the patrol group and other combinations of the aforementioned events.

The main content of the battle is the combination of consecutive and simultaneous fire contacts of border guards with terrorists. Each fire contact of a border guard begins and ends at a previously unknown (random; unpredictable) moment of time and has a previously unknown (random; unpredictable) duration.

Fire contacts have high fluidity, antagonism and unpredictability of results. The outcome of a fire contact can be predicted only with some probability. The results of each fire contact may be expected as follows:

1. killing of a terrorist (with a probability of $P_{e}$ ),

2. failure to kill a terrorist (with a probability of $1-P_{e}$ ),

3. a border guard defeat (with probability of $P^{*}$ ),

4. failure to defeat a border guard (with probability of $1-P^{*}$ ),

5. combinations of outcomes 1-4.

\subsection{Hypotheses and Assumption}

The most essential features of fire contacts may be formulated in the following hypotheses (1-3):

1. each fire contact can result not only in the terrorist kill, but also in the defeat of the border guard; the outcome is unpredictable in advance - it is random,

2. terrorists in the course of fire contacts tend to withdraw from the zones of fire of border guards, they do not concentrate in such fire zones both due to security reasons and because of limited man-carried stock of ammunition,

3. the battle develops in time as a random process. The time points of the beginning, duration, and end of each fire contact are unknown in advance. Therefore, the intervals between the fire contacts are random and, in accordance with the 
well-known theorem of A. Ya. Khinchin [7], are distributed according to a law close to the exponential law.

An assumption. The level of training of each border guard is equally sufficient to fulfil the tasks of the state border guarding. The SRG terrorists also have approximately the same level of training, sufficient to perform the tasks assigned. Therefore, the conditions and the probability of the outcome of fire contacts during the battle do not change through the time. At the first stage of the model construction, we will consider that a terrorist and/or a border guard defeat are possible during a fire contact (in a single battle).

\subsection{Formal Consequences of Hypotheses}

Based on the future results of the model development, there will be a need to assess its adequacy to the real battle processes. Therefore, we firstly consider the possible formal consequences of hypotheses 1-3. For one fire contact between a border guard and a terrorist, let us use the above mentioned notations for the probability of fire contact outcomes. Let us find the mathematical expectation, as the limit to which the mean value of a sample of random variables tends when the sample size tends to infinity, and which has known useful properties, given, for example, in [8], of the number of terrorists killed $N_{e .1}$ and defeated border guards $n_{\text {bg.1 }}$ :

$$
\left.\begin{array}{l}
N_{e .1}=1 \cdot P_{e}+0 \cdot\left(1-P_{e}\right)=P_{e} \\
n_{\mathrm{bg} .1}=1 \cdot P^{*}+0 \cdot\left(1-P^{*}\right)=P^{*}
\end{array}\right\}
$$

The sought-for variables coincided with the probability of the terrorist killing and the border guard defeat respectively.

In order to reveal the internal law of the battle, let us temporarily assume the possibility of forming a corridor which is used by undefeated terrorists to infiltrate through the border into the territory of the state and assume the possibility of unlimited ammunition at the border guards. Let us also suppose that by the time of battle $t$, an average number of fire contacts equaled to $n_{\mathrm{fc}}$. For convenience, let us use complete and simplified notations of the mathematical expectation of the killed number terrorists by time $t$ as $M\left[N_{\mathrm{e}}\right]=N_{\mathrm{e}}$ and defeated border guards as $M\left[n_{\mathrm{bg}}\right]=n_{\mathrm{bg}}$, and we obtain:

$$
\begin{gathered}
M\left[N_{\mathrm{e}}\right]=M\left[\sum_{i=1}^{n_{\mathrm{fc}}} N_{\mathrm{e} .1}\right]=\sum_{i=1}^{n_{\mathrm{fc}}} M\left[N_{\mathrm{e} .1}\right]=\sum_{i=1}^{n_{\mathrm{fc}}} P_{\mathrm{e}}=P_{\mathrm{e}} n_{\mathrm{fc}} \text { then } N_{\mathrm{e}}=P_{\mathrm{e}} n_{\mathrm{fc}} \\
M\left[n_{\mathrm{bg}}\right]=M\left[\sum_{i=1}^{n_{\mathrm{fc}}} n_{\mathrm{bg} .1}\right]=\sum_{i=1}^{n_{\mathrm{fc}}} M\left[n_{\mathrm{bg} .1}\right]=\sum_{i=1}^{n_{\mathrm{fc}}} P^{*}=P^{*} n_{\mathrm{fc}} \text { then } n_{\mathrm{bg}}=P^{*} n_{\mathrm{fc}}
\end{gathered}
$$

Next, let us take into account the limited number $n_{0}$ of border guards within the border patrol group and the condition that the border guard may be defeated by fire of a terrorist during each fire contact. And let us set the fight time to infinity, provided that the border guards have an unlimited supply of ammunition and the number of terrorists, who take turns entering the battle, is not limited. Then, with time, all $n_{0}$ border guards within the patrol group will be defeated. At that moment, the number of fire contacts $n_{\mathrm{fc}}$ will reach its limit $n_{\mathrm{fc} \infty}$ value: 


$$
\lim _{t \rightarrow \infty} n_{\mathrm{bg}}(t)=n_{0} \quad \lim _{t \rightarrow \infty} n_{\mathrm{fc}}(t)=n_{\mathrm{fc} \infty}
$$

Let us substitute the limiting values of $n_{\mathrm{bg}}$ and $n_{\mathrm{fc}}$ from Eq. (4) into the right expression in Eq. (3) and find an estimate of the mathematical expectation of the maximum number of fire contacts until the moment of defeat of all the border guards within the patrol group, as well as the maximum number of fire contacts for one border guard:

$$
n_{0}=P^{*} n_{\mathrm{fc} \infty} \text { then } n_{\mathrm{fc} \infty}=\frac{n_{0}}{P^{*}} \text { and } n_{\mathrm{fc} \infty}\left(n_{0}=1\right)=\frac{1}{P^{*}}
$$

It is not difficult to verify the correctness of the Eq. (5) physical meaning. If the probability of a border guard defeat in one fire contact is equal to one, i.e., $P^{*}=1$, then the mathematical expectation of fire contacts number will coincide with the number of border guards $n_{0}$ within the patrol group.

Substituting the value of the variable $n_{\mathrm{fc} \infty}$ from Eq. (5) into the right expression in Eq. (2), let us find the limiting value of the mathematical expectation of number $N_{\mathrm{e} \infty}$ of killed terrorists until the moment of all the border guards' defeat within the patrol group:

$$
N_{\mathrm{e} \infty}=P_{\mathrm{e}} n_{\mathrm{fc \infty}}=n_{0} \frac{P_{\mathrm{e}}}{P^{*}}
$$

Having the limiting values of the fire contacts number and the casualties of the parties, let us turn to their relative variables:

$$
\begin{aligned}
n_{\mathrm{fc}}^{*}(t) & =\frac{n_{\mathrm{fc}}(t)}{n_{\mathrm{fc} \infty}} \\
N_{\mathrm{e}}^{*}(t) & =\frac{N_{\mathrm{e}}(t)}{N_{\mathrm{e} \infty}} \\
n^{*}(t) & =\frac{n_{\mathrm{bg}}(t)}{n_{0}}
\end{aligned}
$$

If we divide the left and right sides of the right expression in Eq. (3) by the number $n_{0}$ of border guards within the patrol group and take into account the equalities (7) and (9), we can obtain an unexpected result - Eq. (10) of the relative values of the mathematical expectations of defeated border guards' number $n^{*}(t)$ and the number of fire contacts $n_{\mathrm{fc}}^{*}(t)$ :

$$
\frac{n_{b g}(t)}{n_{0}}=\frac{P^{*} n_{\mathrm{fc}}(t)}{n_{0}}=\frac{n_{f c}(t)}{n_{0} / P^{*}} \text { then } n^{*}(t)=\frac{n_{\mathrm{fc}}(t)}{n_{\mathrm{fc} \infty}}=n_{\mathrm{fc}}^{*}(t)
$$

Let us multiply the numerator and denominator of the right side of Eq. (9) by the probability $P_{\mathrm{e}}$ of the terrorist killing as a result of a fire contact, and find the Eq. (11):

$$
n^{*}(t)=\frac{P_{\mathrm{e}} n_{\mathrm{fc}}(t)}{P_{\mathrm{e}} n_{\mathrm{fc} \infty}}=\frac{N_{\mathrm{e}}(t)}{N_{\mathrm{e} \infty}}=N_{\mathrm{e}}^{*}(t)
$$

Eqs (10) and (11) are obtained on the basis of the most essential hypotheses 1-3 for the battle processes by using admissible operations with mathematical expectations 
(5) of random variables which allow us to formulate a new statement about the regular property of the battle process between the border guards of patrol group and the terrorists of SRG.

A consequence of hypotheses 1-3, which concern the most significant features of the fire contacts of border guards with terrorists, is the equality of the relative values of the mathematical expectations of the number of fire contacts and the casualties of the parties at any moment of the battle:

$$
n^{*}(t)=N_{\mathrm{e}}^{*}(t)=n_{\mathrm{fc}}^{*}(t)
$$

which is the internal law of any battle. In this case, the absolute values of these parameters can have different meanings depending on the conditions of the battle.

For the extreme values of time $t$, it is easy to verify the Eq. (12). Indeed, at the beginning of the battle, all variables (7)-(9) in the Eq. (12) are strictly equal to zero. At the time of all border guards' defeat, the values of all these variables become equal to one.

If in the process of verification of the model developed below, the Eq. (12) of the relative casualties of the parties is/were found, such a model can be considered adequate to a real battle with the accuracy of hypotheses 1-3 on the most essential properties of battle processes. Otherwise, the model adequacy becomes doubtful and the application of such a model becomes inappropriate.

\subsection{Simplest Model of Individual Border Guard's Battle with Terrorists}

Let us list possible states $S_{i j}$ of border guard during the battle, essential for the purposes of his actions, that is, those states that differ in the possibility of opening fire at the "next" terrorist.

In the state designation $S_{i j}$, the first index $i$ is used to indicate the number of defeated border guards in this state, the second index $j$ is used to indicate the number of terrorists being fired at in this state:

- $S_{00}$ - a border guard is not defeated, and is free,

- $S_{01}$ - a border guard is not defeated, and is firing at one terrorist,

- $S_{10}-$ a border guard is defeated and cannot shoot the terrorists.

We can obtain the diagram of the individual border guard's battle simplest model (Fig. 1), where the transition from the state $S_{00}$ to the state $S_{01}$ is possible upon detection of another terrorist and is characterized by the intensity (frequency) of the fire contacts $I$.

Each fire contact can continue for random time $T_{\text {random }}$, and can end due to one or a combination of the above mentioned and other reasons. In accordance with the known limit theorem of A. Ya. Khinchin [7], this feature allows us to affirm the distribution of the fire contact duration according to a law close to the exponential law with the mathematical expectation $T_{\mathrm{avr}}$, with $\mu$ parameter and with the intensity $I$ of fire contact occurrence:

$$
M\left[T_{\text {random }}\right]=T_{\text {avr }} \quad \mu=\frac{1}{T_{\text {avr }}} \quad I=\frac{N_{\text {tr }}}{L_{\text {str }}} v_{\text {tr }}
$$

When assessing the intensity $I$, the number of terrorists in the group $N_{\text {tr }}$, the strip width $L_{\text {str }}$ to be overcome by the terrorists within the zone of fire of border guards and the average speed of movement $v_{\text {tr }}$ of terrorists across this strip are taken into account. 


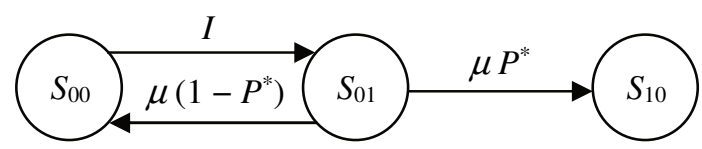

Fig. 1 Diagram of simplest model of border guard battle with terrorists

Each fire contact can result in the defeat of the border guard with probability $P^{*}$ and the transition of the process (Fig. 1) from the state $S_{01}$ to the state $S_{10}$, or with probability $1-P^{*}$ can have a successful outcome for the border guard, which leads to the transition from the state $S_{01}$ to the state $S_{00}$.

The exponential distribution of random variables in the battle process under consideration makes it possible to seek its analytic description in the class of Markov processes with continuous time and discrete states. Therefore, let us set up a system of Kolmogorov-Chapman differential equations [7] for the probabilities $P_{i j}$ of the states $S_{i j}$ of the battle model (Fig. 1), where, for convenience, let us denote derivatives by a point over the probabilities of the states and omit the dependence of probabilities on time as follows:

$$
\left.\begin{array}{l}
\dot{P}_{00}=-I P_{00}+\mu\left(1-P^{*}\right) P_{01} \\
\dot{P}_{01}=-\mu P_{01}+I P_{00} \\
\dot{P}_{10}=\mu P^{*} P_{01}
\end{array}\right\}
$$

Let us integrate the equations' system (14) under initial conditions:

$$
P_{00}(t=0)=1 ; \quad P_{01}(t=0)=P_{10}(t=0)=0
$$

We will get:

$$
\left.\begin{array}{l}
P_{00}=C_{1} \mathrm{e}^{\lambda_{1} \mu t}+C_{2} \mathrm{e}^{\lambda_{2} \mu t} \\
P_{01}=\frac{\rho}{\alpha}\left[\mathrm{e}^{\lambda_{1} \mu t}-\mathrm{e}^{\lambda_{2} \mu t}\right] \\
P_{10}=1-\frac{1}{\alpha}\left[\lambda_{1} \mathrm{e}^{\lambda_{2} \mu t}-\lambda_{2} \mathrm{e}^{\lambda_{1} \mu t}\right]
\end{array}\right\}
$$

where

$$
\rho=\frac{I}{\mu} ; \quad \alpha=\sqrt{1+\rho^{2}+2 \rho\left(1-2 P^{*}\right)} ; \quad C_{1,2}=\frac{\alpha \pm(1-\rho)}{2 \alpha} ; \quad \lambda_{1,2}=\frac{ \pm \alpha+(1+\rho)}{2}
$$

The mathematical expectation of the number $n_{\mathrm{fc}}$ of fire contacts (of the attacked terrorists of the SRG) by the time of the battle $t$ will be determined taking into account the time of the border guard's stay in the occupied state $S_{01}$ and its "productivity" $\mu$ :

$$
n_{\mathrm{fc}}(t)=\mu \int_{0}^{t} P_{01}(\tau) \mathrm{d} \tau=\frac{1}{P^{*}}\left[1-\frac{1}{\alpha}\left(\lambda_{1} \mathrm{e}^{\lambda_{2} \mu t}-\lambda_{2} \mathrm{e}^{\lambda_{1} \mu t}\right)\right]
$$




\subsection{Verification of the Battle Simplest Model}

The maximum possible value of the mathematical expectation of the number of fire contacts for the entire time until the moment of the border guard's defeat can be found, passing to the limit in the Eq. (18):

$$
n_{\mathrm{fc} \infty}=\lim _{t \rightarrow \infty} n_{\mathrm{fc}}(t)=\frac{1}{P^{*}}\left(1-\frac{1}{\alpha} \cdot 0\right)=\frac{1}{P^{*}}
$$

Let us note that the result (19) has coincided with the value (5) obtained earlier for this variable concerning one border guard.

In order to verify the adequacy of battle model Eqs (16)-(19) of an individual border guard, let us find the relative value of the mathematical expectation for the number of fire contacts at any time $t$ of the battle. To this end, let us divide the left side of Eq. (18) into the left side of Eq. (19) and the right side of Eq. (18) by the right side of Eq. (19), then we get:

$$
\frac{n_{\mathrm{fc}}(t)}{n_{\mathrm{fc} \infty}}=\frac{1}{P^{*}}\left[1-\frac{1}{\alpha}\left(\lambda_{1} \mathrm{e}^{\lambda_{2} \mu t}-\lambda_{2} \mathrm{e}^{\lambda_{1} \mu t}\right)\right]\left(\frac{1}{P^{*}}\right)^{-1}
$$

After reducing the same variables, we will find:

$$
n_{\mathrm{fc}}^{*}(t)=1-\frac{1}{\alpha}\left(\lambda_{1} \mathrm{e}^{\lambda_{2} \mu t}-\lambda_{2} \mathrm{e}^{\lambda_{1} \mu t}\right)
$$

The relative value of the mathematical expectation $n^{*}(t)$ of the number of defeated border guards at any time of the battle $t$ is found taking into account the known properties of the mathematical expectation of random variables [8]:

$$
n^{*}(t)=\frac{n_{\mathrm{bg}}(t)}{n_{0}}=\frac{n_{\mathrm{bg}}(t)}{1}=n_{\mathrm{bg}}(t)=0 \cdot\left[P_{00}(t)+P_{01}(t)\right]+1 \cdot P_{10}(t)=P_{10}(t)
$$

Thus, the relative value of the mathematical expectation of the number of defeated border guards at any time is equal to the probability of the state $P_{10}$ :

$$
n^{*}(t)=P_{10}(t)=1-\frac{1}{\alpha}\left(\lambda_{1} \mathrm{e}^{\lambda_{2} \mu t}-\lambda_{2} \mathrm{e}^{\lambda_{1} \mu t}\right)
$$

Comparing Eqs (21) and (23), we can see that they are identical:

$$
n^{*}(t)=n_{\mathrm{fc}}^{*}(t)
$$

Using Eqs (2), (6) and (8) we can see that the expression for the relative value of the mathematical expectation $N_{\mathrm{e}}{ }^{*}(t)$ of the number of killed terrorists differs from the expression for $n_{\mathrm{fc}}{ }^{*}(t)$ by the probability of the terrorist kill and, at the same time, it coincides with Eq. (21):

$$
N_{\mathrm{e}}^{*}(t)=\frac{N_{\mathrm{e}}(t)}{N_{\mathrm{e} \infty}}=\frac{P_{\mathrm{e}} n_{\mathrm{fc}}(t)}{P_{\mathrm{e}} n_{\mathrm{fc} \infty}}=\frac{n_{\mathrm{fc}}(t)}{n_{\mathrm{fc} \infty}}=n_{\mathrm{fc}}^{*}(t)
$$

Based on Eqs (19)-(25), it can be stated that there is the presence of equality of relative values of the mathematical expectations number of fire contacts and losses of the sides

$$
n^{*}(t)=N_{\mathrm{e}}^{*}(t)=n_{\mathrm{fc}}^{*}(t)
$$


in the analytical description Eqs (14)-(18) of the simplest battle model.

Thus, the obtained simplest model of the battle of an individual border guard proves to be adequate to a real battle with the accuracy of accepted hypotheses 1-3 concerning the most significant features of the battle. This allows us to return to the main goal of the research, i.e. to assess the size of the ammunition load needed for the border guards within a patrol group in the course of battle with sabotage and reconnaissance group until reinforcement approaches.

In the zero approximation, we can assume that each of the border guards within the patrol group will have to fight not with all of the terrorists $N_{\text {tr }}$ of the SRG, but only with a part of them, which leads to a decrease in the initial intensity of the fire contacts in $n_{0}$ times:

$$
I_{1}=I / n_{0}
$$

\subsection{Searching for Border Patrol Group Ammunition Amount}

The regular ammunition load to the border guard's weapons of the patrol group has a weight of $Q_{\mathrm{alw}}$ and it can provide $F_{\mathrm{fc}}$ fire contacts on average. However, during the battle, casualties of terrorists of the SRG and the border guards are possible. The goal of the battle is to defeat the opposite party. Hence, the end of the battle occurs at the time of $t_{\mathrm{cr}}$, when there is a decrease in the numerical strength of the group to a threshold level $\beta$, at which its fighting efficiency is lost:

$$
n^{*}\left(t_{\mathrm{cr}}\right)=\frac{n_{\mathrm{bg}}\left(t_{\mathrm{cr}}\right)}{n_{0}} \geq \beta
$$

Using the lower limit state for the parameter $\beta$ it is not difficult to find the number of fire contacts and casualties of the parties at that time without performing complex calculations, if we use Eq. (12) and Eqs (7)-(9):

$$
n_{\mathrm{fc}}\left(t_{\mathrm{cr}}\right)=\beta n_{\mathrm{fc} \infty}=\beta \frac{n_{0}}{P^{*}} ; \quad N_{\mathrm{e}}(t)=\beta N_{\mathrm{e} \infty}=\beta n_{0} \frac{P_{\mathrm{e}}}{P^{*}} ; \quad n_{\mathrm{bg}}\left(t_{\mathrm{cr}}\right)=\beta n_{0}
$$

The expressions (28) will take the following form for an individual border guard:

$$
n_{\mathrm{fc}}\left(t_{\mathrm{cr}}\right)=\beta n_{\mathrm{fc} \infty}=\frac{\beta}{P^{*}} ; \quad N_{\mathrm{e}}(t)=\beta N_{\mathrm{e} \infty}=\beta \frac{P_{\mathrm{e}}}{P^{*}} ; \quad n_{\mathrm{bg}}\left(t_{\mathrm{cr}}\right)=\beta
$$

The sufficiency of the existing ammunition load of an individual border guard can be verified taking into account Eq. (29) from the inequality (30):

$$
F_{\mathrm{c}} \geq \frac{\beta}{P^{*}}
$$

The assessment of time duration $t_{\mathrm{F}}$, in the course of which an existing ammunition load can be consumed from the Eq. (31) by taking into account Eq. (18):

$$
F_{\mathrm{c}}=\frac{1}{P^{*}}\left[1-\frac{1}{\alpha}\left(\lambda_{1} \mathrm{e}^{\lambda_{2} \mu t_{F}}-\lambda_{2} \mathrm{e}^{\lambda_{1} \mu t_{F}}\right)\right]
$$

The assessment of the parameters $\left(P_{\mathrm{e}}, P^{*}, T_{\mathrm{avr}}\right)$ of the level of the border guards training within the patrol group is not difficult and is carried out during their professional training. The inequality (30) shows that border guards having a higher level of training (with a lower probability value $P^{*}$ of defeat) have a greater potential number 
of fire contacts and may need a bigger ammunition load. The limitation in this case is the total weight $Q_{\mathrm{w}}$ of the ammunition load $Q_{\mathrm{alw}}$ and the standard equipment $Q_{\text {st.eq }}$, which should not exceed the physiologically acceptable value $Q_{\mathrm{m}}$ :

$$
Q_{\mathrm{w}}=\left(Q_{\mathrm{alw}}+Q_{\text {st.eq }}\right) \leq Q_{\mathrm{m}}
$$

However, the battle mission fulfilment depends on the possibility of the timely arrival of reinforcements to the place of the patrol group battle with the SRG. The arrival time $t_{\text {ar.t }}$ is determined by the preparation time $t_{\text {pr.t }}$ of the alert forces to the departure and the duration $t_{\mathrm{mv}}$ of the en-route movement to the battlefield at the distance of $D_{\mathrm{mv}}$ with the average speed of $v$ :

$$
t_{\text {ar.t }}=t_{\text {pr.t }}+t_{\mathrm{mv}}=t_{\text {pr.t }}+\frac{D_{\mathrm{mv}}}{v}
$$

The critical time value, at the expiration of which the battle capability of the border guards patrol group can be lost, can be calculated from Eq. (34):

$$
P_{10}\left(t_{\text {cr }}\right) \geq \beta \text { then } \frac{1}{\alpha}\left(\lambda_{1} \mathrm{e}^{\lambda_{2} \mu t_{\text {cr }}}-\lambda_{2} \mathrm{e}^{\lambda_{1} \mu t_{\text {cr }}}\right)=1-\beta
$$

If the critical time $t_{\mathrm{cr}}$ of the border guards patrol group battle capability loss or the time $t_{\mathrm{F}}$ of the ammunition consumption is less than the arrival time of the reinforcement:

$$
\left(t_{\mathrm{F}}<t_{\text {ar.t }}\right) \cup\left(t_{\text {cr }}<t_{\text {ar.t }}\right)
$$

then terrorists of the SRG may be in time to $\left(t_{F}<t_{a r . t}\right) \cup\left(t_{c r}<t_{a r . t}\right)$ defeat the border guards of the patrol group and cross the state border, thus violating the defence of the state border. Preliminary assessments allow each time to receive the value of the maximum possible "safe" remoteness of the patrol group from the location of the border guards' alert forces. If Eq. (35) is true, either the length of the patrol group's route should be reduced, or the border guards with a higher level of training and with increased ammunition load should be assigned to the border patrol group. The amount of the ammunition load of such a border guard must ensure that the average number of fire contacts is fulfilled (18) not less than the value obtained from the Eq. (36):

$$
n_{\text {fc }}\left(t_{\text {ar.t }}\right)=\frac{1}{P^{*}}\left[1-\frac{1}{\alpha}\left(\lambda_{1} \mathrm{e}^{\lambda_{2} \mu t_{\text {ar.t }}}-\lambda_{2} \mathrm{e}^{\lambda_{1} \mu t_{\text {ar.t }}}\right)\right]
$$

If the condition (35) is true, the increase $\Delta F_{\text {inc }}$ of the existing $Q_{\text {alw }}$ ammunition load and the final weight $Q_{\mathrm{fw}}$ al of the ammunition load can be estimated from Eq. (37):

$$
\Delta F_{\mathrm{inc}}=\frac{n_{\mathrm{fc}}\left(t_{\mathrm{ar.t}}\right)-F_{\mathrm{c}}}{F_{\mathrm{c}}} ; \quad Q_{\mathrm{fw} \mathrm{al}}=Q_{\mathrm{a} \mathrm{w}_{\mathrm{w}}}\left(1+\Delta F_{\mathrm{inc}}\right)
$$

The new weight of the ammunition load should be checked by Eq. (32) for its admissibility (see new $Q_{\text {alw }}=Q_{\text {fw al }}$ ).

The considered simplest model allows obtaining assessments of the size (see Eq. (37)) of the ammunition load needed by the patrol group in order to conduct battle with a sabotage and reconnaissance group prior to the reinforcement approach. But this model does not take into account the information component of the battle, which is related to the timely detection of the terrorists by the border detail guard, and can be 
assessed by the probability $P_{\mathrm{d}}$ for timely detection and reduce the capabilities of the patrol group.

So, untimely detected terrorist can attack and defeat the border guard with impunity who is in the state of $S_{00}$ i.e. "the border guard is not defeated and is free". Such an event is not reliable and it can be assessed by the probability $P_{\mathrm{h}}$ of the border guard's defeat with impunity. Nevertheless, it does not change the logic of assessing the casualties of the parties and the needs of the border guards in the ammunition load, but it determines the need to refine the model.

\subsection{Complete Model of Battle and Verification of its Adequacy}

A complete model of the battle between an individual border guard and terrorists of the SRG is shown in Fig. 2.

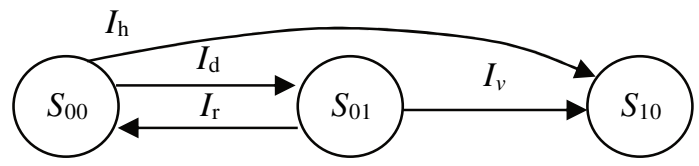

Fig. 2 Diagram of complete model for a border guard battle with terrorists

The intensities of the transitions (see Eq. (38)) within the complete battle model (Fig. 2) take into account all known versions of fire contacts, i.e. duel fight and battles with consideration of terrorists' impunity and have the following form:

$$
I_{\mathrm{d}}=I P_{\mathrm{d}} ; \quad I_{\mathrm{h}}=I\left(1-P_{\mathrm{d}}\right) P_{\mathrm{h}} ; \quad I_{\mathrm{r}}=\mu\left(1-P^{*}\right) ; \quad I_{\mathrm{v}}=\mu P^{*}+I_{\mathrm{h}}
$$

This model (Fig. 2) is described by a system of linearly independent Kolmogorov-Chapman differential equations:

$$
\left.\begin{array}{l}
\dot{P}_{00}=-\left(I_{\mathrm{h}}+I_{\mathrm{d}}\right) P_{00}+I_{\mathrm{r}} P_{01} \\
\dot{P}_{01}=I_{\mathrm{d}} P_{00}-\left(I_{\mathrm{r}}+I_{\mathrm{v}}\right) P_{01}
\end{array}\right\}
$$

which are integrated under the initial conditions (15), where $P_{10}=1-P_{01}-P_{00}$ :

$$
\left.\begin{array}{l}
P_{00}=C_{1} \mathrm{e}^{\lambda_{1} t}+C_{2} \mathrm{e}^{\lambda_{2} t} \\
P_{01}=\frac{a_{21}}{\alpha}\left[\mathrm{e}^{\lambda_{1} t}-\mathrm{e}^{\lambda_{2} t}\right] \\
P_{10}=1-\frac{1}{2 \alpha}\left[(\alpha+\delta) \mathrm{e}^{\lambda_{1} t}+(\alpha-\delta) \mathrm{e}^{\lambda_{2} t}\right]
\end{array}\right\}
$$

where $a_{i j}$ and $C_{12}$ are the coefficients:

$$
\left.\begin{array}{lll}
a_{11}=-\left(I_{\mathrm{h}}+I_{\mathrm{d}}\right) & a_{12}=I_{\mathrm{r}}=\mu\left(1-P^{*}\right) & C_{1}=\frac{I_{\mathrm{d}}+I_{\mathrm{h}}+\lambda_{2}}{\lambda_{2}-\lambda_{1}} \\
a_{21}=I_{\mathrm{d}}=I P_{\mathrm{d}} & a_{22}=-\left(I_{\mathrm{r}}+I_{\mathrm{v}}\right) & C_{2}=\frac{-I_{\mathrm{d}}-I_{\mathrm{h}}-\lambda_{1}}{\lambda_{2}-\lambda_{\mathrm{l}}}
\end{array}\right\}
$$

$\lambda_{1}$ and $\lambda_{2}$ are the roots of the characteristic equation: 


$$
\begin{gathered}
\lambda_{1,2}=\frac{\left(a_{11}+a_{22}\right) \pm \alpha}{2} \quad \delta=\left(a_{11}-a_{22}\right) \\
\alpha=\sqrt{\left(a_{11}+a_{22}\right)^{2}-4\left(a_{11} a_{22}-a_{21} a_{12}\right)}
\end{gathered}
$$

The mathematical expectation of the fire contacts number at any time of the battle Eq. (43) is analogous to the Eq. (18):

$$
n_{\mathrm{fc}}(t)=\mu \int_{0}^{t} P_{01}(\tau) \mathrm{d} \tau=\frac{\mu a_{21}}{\lambda_{1} \lambda_{2} \alpha}\left(\lambda_{2} \mathrm{e}^{\lambda_{1} t}-\lambda_{1} \mathrm{e}^{\lambda_{2} t}+\alpha\right)
$$

and it has a limiting value:

$$
n_{\mathrm{fc} \infty}=\lim _{t \rightarrow \infty} n_{\mathrm{fc}}(t)=\frac{\mu a_{21}}{\lambda_{1} \lambda_{2}}
$$

It is obvious that the complete model is also characterised by the condition of equality of the normalized values for the mathematical expectations of the fire contacts number and losses of the parties Eq. (12). When the probability $P_{\mathrm{d}}$ of detecting terrorists in the course of the battle tends to one unit, all the calculated Eqs (40)-(44) automatically switch to the form of the expressions considered for the simplest model of the battle.

However, in the case of a more complete account of the conditions of the battle, one should use Eq. (45) instead of Eq. (36):

$$
n_{\text {fc }}\left(t_{\text {ar.t }}\right)=\frac{\mu a_{21}}{\lambda_{1} \lambda_{2} a}\left(\lambda_{2} \mathrm{e}^{\lambda_{1} t_{\text {ar.t }}}-\lambda_{1} \mathrm{e}^{\lambda_{2} t_{\text {ar.t }}}+\alpha\right)
$$

\subsection{Verification of Battle Model Suitability for Practical Calculations}

In order to test the suitability of the developed model for its intended use, let us perform calculations for conditions close to possible real-life conditions.

The reinforced patrol group of four border guards should patrol a $20 \mathrm{~km} \mathrm{long} \mathrm{sec-}$ tor of the state border. The most difficult variant of the task execution includes the possibility of identifying a sabotage and reconnaissance group, consisting of seven terrorists at the maximum distance from the place of permanent disposition of the border guard subunit. The values of the border guards training level parameters were assessed during their professional training and are presented in Tab. 1. This table also shows all initial data in the form of the notations used in this text, as well as the results of calculations using the Eqs (38)-(45) of the complete model of the battle.

The size of the border guard ammunition load (Tab. 1, item 16) in this example allows him to conduct battle on average for 23 minutes (Tab. 1, item 36). This means that the ammunition load will be consumed 5 minutes earlier then the expiration of the critical time (Tab. 1, item 35) and prior to the 26 min arrival time of reinforcements (Tab. 1, item 34). As a result, we can expect a defeat of the patrol group and crossing of the state border by terrorists.

Increasing the present size of the ammunition load by $30 \%$ to $F_{\mathrm{fc}}=2$ allows increasing the average time until the consumption of the ammunition (Tab. 1, item 40) and ensuring the sustainability of the task accomplishment on the state border guarding until reinforcements arrival time. 
Tab. 1 Data and calculation results using the battle model

\begin{tabular}{|l|l|c|l|l|c|l|l|c|l|l|c|}
\hline No & Argument & Value & No & Argument & Value & No & Argument & Value & No & Argument & Value \\
\hline 1 & $n_{0}$ & 4 & 11 & $T_{\text {avr }},[\mathrm{min}]$ & 0.5 & 21 & $I_{\mathrm{d}},[1 / \mathrm{min}]$ & 0.127 & 31 & $\delta$ & 2.1277 \\
\hline 2 & $\beta$ & 0.75 & 12 & $\mu,[1 / \mathrm{min}]$ & 2 & 22 & $I_{\mathrm{h}},[1 / \mathrm{min}]$ & 0.012 & 32 & $\alpha$ & 2.05193 \\
\hline 3 & $N_{\mathrm{tr}}$ & 7 & 13 & $D_{\mathrm{mv}},[\mathrm{km}]$ & 20 & 23 & $I_{\mathrm{r}},[1 / \mathrm{min}]$ & 1.38 & 33 & $n_{\mathrm{fc} . \infty}$ & 2.3987 \\
\hline 4 & $L_{\text {str }},[\mathrm{m}]$ & 200 & 14 & $v,[\mathrm{~km} / \mathrm{h}]$ & 55 & 24 & $I_{\mathrm{v}},[1 / \mathrm{min}]$ & 0.632 & 34 & $t_{\text {ar.t }},[\mathrm{min}]$ & 26.818 \\
\hline 5 & $v_{\mathrm{tr}},[\mathrm{m} / \mathrm{min}]$ & 20 & 15 & $t_{\text {pr.t }},[\mathrm{min}]$ & 5 & 25 & $a_{11}$ & -0.14 & 35 & $t_{\mathrm{cr}},[\mathrm{min}]$ & 28 \\
\hline 6 & $P^{*}$ & 0.31 & 16 & $F_{\mathrm{fc}}$ & 1.5 & 26 & $a_{12}$ & 1.38 & 36 & $t_{\mathrm{F}},[\mathrm{min}]$ & 23.285 \\
\hline 7 & $P_{\mathrm{e}}$ & 0.69 & 17 & $Q_{\text {st.eq }},[\mathrm{kg}]$ & 22.5 & 27 & $a_{21}$ & 0.127 & 37 & $P_{10}\left(t_{\mathrm{cr}}\right)$ & 0.7534 \\
\hline 8 & $P_{\mathrm{d}}$ & 0.73 & 18 & $Q_{\mathrm{alw}},[\mathrm{kg}]$ & 4.1 & 28 & $a_{22}$ & -2.01 & 38 & $n_{\mathrm{bg}}$ & 3.01 \\
\hline 9 & $I,[1 / \mathrm{min}]$ & 0.7 & 19 & $Q_{\mathrm{w}},[\mathrm{kg}]$ & 26.6 & 29 & $\lambda_{1}$ & -0.05 & 39 & $N_{\mathrm{e}}$ & 4.98 \\
\hline 10 & $I_{1},[1 / \mathrm{min}]$ & 0.175 & 20 & $Q_{\mathrm{m}},[\mathrm{kg}]$ & 28 & 30 & $\lambda_{2}$ & -2.10 & 40 & $N e w t_{\mathrm{F} .}[\mathrm{min}]$ & 31.047 \\
\hline
\end{tabular}

At the same time, the weight of the ammunition load (Tab. 1, item 18) will be increased to $5.47 \mathrm{~kg}$, resulting in the total weight of the equipment equal to $27.97 \mathrm{~kg}$ and not exceeding the admissible weight of $28 \mathrm{~kg}$ (Tab. 1, item 20).

\section{Results}

The developed and verified Markov models of the defensive battle of the border guards of the Patrol Group with the terrorists of the SRG trying to overcome the state border, contain calculating expressions that allow to evaluate the expected results of the battle. In addition, these expressions can help to reasonably choose the values of the parameters, listed in the text and necessary for organizing the defence of the state border including potential penetration of armed groups of terrorists and sabotage and reconnaissance groups. Having developed such a model, the goal of our research can be considered to be achieved.

In the course of research, the internal law of battle was discovered, namely the equality of the relative values of math expectations of fire contacts number and losses of the parties at any time in the battle. The noted equality became one of the criteria for checking the adequacy of the models, being developed to the actual process of the battle, taking into account the hypotheses about its most essential features. The discovery of the mentioned equality in the analytical description of the developed models makes it possible to consider these models as adequate to the actual battle process with the accuracy of hypotheses about the most significant features of the battle, which, in turn, makes it possible to consider the second goal of the article - models verification - to be achieved.

\section{Conclusions}

The models of battle of a border guard with terrorists include consideration of the following battle conditions: a potential number of terrorists in the sabotage and reconnaissance group, the randomness of the start and end time of each fire contact, the randomness of the fire contact results, the distance of the battlefield from the border subunit location, parameters of the border guards training level, the number and weight of ammunition and standard equipment of the border guards and other parameters of battle conditions.

The developed models are multiparameter and allow to carry out research to find rational values of the parameters that determine the characteristics of the organization 
of patrols and defence of the state border. Moreover, they allow to create individual recommendations for professional training for each border guard.

The given example for of the conditions close to the real-life conditions of the protection and defence of the state border showed the possibility of using the model to assess the degree of compliance of the frontier guard's amount of ammunition and the current situation of a possible battle with SRG terrorists.

The example also shows the possibility of calculating and changing the amount of the ammunition of border guards to a level sufficient to accomplish the task of defending the state border. The same results can be obtained due to changes in other parameters.

The analytical description of the simplest and complete Markov model of a border guard battle with terrorists allows to use models for organizing the defence of the state border in real-time.

\section{References}

[1] Who and How Guards the Border of the United States of America (in Russian) [online]. [viewed 2020-09-12]. Available from: http://dsx-oder.blogspot.com/ 2012/03/blog-post_7509.html

[2] Losses of Ukrainian Border Guards Since the Beginning of the Anti-Terrorist Operation Have Exceeded 500 People (in Russian) [online]. [viewed 2020-09-12]. Available from: https://novorosinform.org/714348

[3] MYSYK, A.B. Methodology of Planning Border Operations During the Participation of Formations of the State Border Guard Service of Ukraine in Territorial Defence (in Ukrainian) [online]. Collection of Scientific Works of NA SBGSU, 2017, 3, pp. 106-115. [viewed 2020-09-12]. Available from: https://nadpsu. edu.ua/wp-content/uploads/2018/11/sbirnik_3_2017_vtn.pdf

[4] ANDRUSHKO, O.V. Problems of Counteraction to Sabotage and Reconnaissance Groups by Subunits of the State Border Guard Service of Ukraine at the Border and in the Zone of Anti-Terrorist Operation (in Ukrainian) [online]. Collection of Scientific Works of NA SBGSU, 2017, 3, pp. 19-28. [viewed 2020-0912]. Available from: https://nadpsu.edu.ua/wp-content/uploads/2018/11/ sbirnik_3_2017_vtn.pdf

[5] GORODNOV, V.P. and Yu.E. REPILO. Assessment of the Impact of the Timeliness of Material Support on the Combat Capabilities of Grouping of Troops in Battle (Operations) (in Ukrainian) [online]. Collection of Scientific Works of NA $S B G S U$, 2017, 2, pp. 44-54. [viewed 2020-09-12]. Available from: https://nadpsu.edu.ua/wp-content/uploads/2018/11/sbirnik_2_2017_vtn.pdf

[6] GORODNOV, V.P. and S.P. YAROSH. Estimation of Influence of Levels of Completeness of Material Maintenance on Value of an Indicator of Bioenergetics Potential of Interspecific Tactical Group (in Ukrainian) [online]. Collection of Scientific Works of NA SBGSU, 2017, 2, pp. 55-69. [viewed 2020-09-12]. Available from: https://nadpsu.edu.ua/wp-content/uploads/2018/11/sbirnik_2_2017_vtn.pdf

[7] GORODNOV, V.P. Theoretical Bases of Modelling of Microeconomic and Other Processes and Systems (in Russian). Kharkov: Publishing House of the Ministry of Internal Affairs of Ukraine, 2009. ISBN 978-966-8558-23-8. 
[8] GORODNOV, V.P. Higher Mathematics (in Simple Language, With Examples): a Textbook for Students of Economic Specialties of Higher Educational Establishments (in Ukrainian). $3^{\text {rd }}$ ed. Kharkov: Publishing House of the Ministry of Internal Affairs of Ukraine, 2013. ISBN 978-966-8558-45-0. 